\title{
Brain Natriuretic Peptide in Cirrhosis
}

\section{Ana Lanca Bastiancic ${ }^{1 *}$ and Sandra Milic ${ }^{2}$}

${ }^{1}$ Department of Cardiology, Thalassotherapia Opatija, Clinic for treatment, rehabilitation and prevention of cardiovascular disease, Opatija, Croatia

${ }^{2}$ Department of Gastroenterology, University of Rijeka School of Medicine, University Hospital Centre Rijeka, Rijeka, Croatia

\begin{abstract}
Brain natriuretic peptide (BNP) is well known cardiac hormone released from the left ventricle myocardium as result of heart wall injury. It is a often used biochemical marker of heart failure. Its greatest role is in distinguishing etiology of dyspnea. The role of BNP in cirrhotic patients is not fully explored jet. It is well known that cirrhosis leads to diastolic and consequently systolic dysfunction, causing increase of BNP values. BNP could be a good follow up marker in cirrhotic patients, and a marker od liver decompensation, since its values positively correlate with Child Pough score, and other complications of liver cirrhosis. There are more studies needed in this field.
\end{abstract}

\author{
Publication History: \\ Received: January 21, 2016 \\ Accepted: April 23, 2016 \\ Published: April 25, 2016

\section{Keywords:} \\ Brain natriuretic peptide, Heart \\ failure, Diastolic dysfunction, \\ Cirrhosis.
}

\section{Introduction}

Brain natriuretic peptide (BNP) is a 32-amino acid peptide, cardiac hormone produced from the left ventricle as repercussion to left ventricular diastolic dysfunction. It is a biochemical marker of diastolic heart failure [1], which can be diagnosed if there are symptoms of congestive heart failure, normal or mildly abnormal left ventricular systolic function, and evidence of abnormal left ventricular relaxation, filling, diastolic distensibility or diastolic stiffness [2].

Since the signs and symptoms of heart failure are not so specific, and the patients are mainly presenting with shortness of breath or dyspneathat can be caused by many pulmonary disease including chronic obstructive pulmonary disease exacerbation and respiratory distress, it is a great parameter in distinguishing heart failure and pulmonary etiology of symptoms. Many studies have searched for threshold concentration of BNP that excludes heart failure. They found values that differ acute failure including also worsening of chronic failure with cut-off point of $100 \mathrm{pg} / \mathrm{mL}$, form chronic heart failure with cut-off point of $35 \mathrm{pg} / \mathrm{mL}$ [3]

BNP is of great use in emergency departments and intensive care units [4] where this kind of patients are very frequent, and sometimes severe. Recent studies showed the importance of BNP in critical care units as predictor of severity of disease and outcome in patients with non-cardiogenic pulmonary edema [5], severe sepsis [6], and chronic hypercapnic respiratory failure patients [7]. It is also pointed out its importance in predicting need for intensive care treatment in patients with acute exacerbation of chronic obstructive pulmonary disease [8]. These diseases are often followed by heart failure, and also the elevation of BNP.

There are many non-cardiac diseases affecting diastolic heart function, resulting pressure and volume overload, and consequently increase level of BNP, such as renal failure, various pulmonary disease, anemia, type two diabetes mellitus and chronic liver disease (9). In some of these situations, if a patient has a bearing cardiac disease, these values will be much higher, since that diseases act like precipitating factor for cardiac decompensation. If there is no coexisting cardiac disease, values barely reach cut-off values.

BNP is sensitive and specific, simple and accessible test for diagnosing heart failure $[10,11]$. It is a good follow up marker, and indicator for long term mortality [12]. Patients with chronic heart failure in some cases, according to severity and irreversibility of cardiac changes, have permanently elevated BNP, and so its values can be a good prognostic, and follow up marker. Higher BNP levels are linked with poor outcome, worst prognosis and higher mortality rate [13]. The measured value correlates with severity of disease and its prognosis $[14,15]$.

\section{Cirrhosis and cirrhotic cardiomiopathy}

The cause of this paper is to explore the value of BNP in cirrhosis from the available literature.It is well known that cirrhosis affects diastolic heart function. According to that we can expect in some stages of disease elevation of BNP. Progression of the disease leads to many hemodynamic changes and consequently diastolic heart failure, with high left atrial pressure, lower cardiac output and higher peripheral vascular resistance[16-18].

Cirrhosis leads to enlargement of atrium, increasement of end diastolic atrial pressure, and consequently diastolic dysfunction. The first detectable heart complication of cirrhosis is impaired relaxation, or second grade diastolic dysfunction.Progression of disease leads to progression of diastolic dysfunction to pseudo-normalisation and the fourth grade known as restriction, which at the beginning reversible and thereafter irreversible. The higher stage is related to worse prognosis, so these patients should be monitored more often.Over time, that volume overload, high end diastolic volume, and diastolic dysfunction with large left atrium, leads to cardiac abnormalities, such as, mitral regurgitation, tricuspidal regurgitation and secondary pulmonary hypertension and portal pressure increase. All this abnormalities cause heart failure with preserved ejection fraction leading to heart failure with reduced left ventricle ejection fraction $[2,19]$.

${ }^{*}$ Corresponding Author: Dr. Ana Lanca Bastiancic, Department of Cardiology, Thalassotherapia Opatija, Clinic for treatment, rehabilitation and prevention of cardiovascular disease, Opatija, Croatia, Tel: +385958621080; E-mail: analanca22@gmail.com

Citation: Bastiancic AL, Milic S (2016) Brain Natriuretic Peptide in Cirrhosis. Int J Community Fam Med 1: 107. doi: http://dx.doi.org/10.15344/ijcfm/2016/107

Copyright: (c) 2016 Bastiancic et al.This is an open-access article distributed under the terms of the Creative Commons Attribution License, which permits unrestricted use, distribution, and reproduction in any medium, provided the original author and source are credited. 
Cardiac abnormalities as repercussion to cirrhosis are described as entity called "cirrhotic cardiomyopathy" [20,21], for the first time described at the end of the eighties. This complication is described in $40-50 \%$ of all cirrhotic patients. It can be detected by using electrocardiogram, transthoracic echocardiography, and BNP measures [19].There is no specific therapy for that state, only liver transplantation could be curative [19,22-23]. There is no underlying cardiac disease detected in these patients.

\section{Role of BNP in cirrhosis}

Progression of cirrhosis leads todiastolic heart failure, at first with preserved ejection fraction, and after words with reduced left ventricle ejection fraction, causing BNP releasing, whose values are in correlation with the severity of cirrhosis and diastolic cardiac dysfunction [20,24].The main cause of BNP release is increasement of the left atrium volume, leading to myocardiocyte stretching [20]. There is one study pointing that BNP could be an early indicator of cirrhosis in patients with hepatocellular diseases and might also be related to the severity of the cirrhosis [25]. BNP values are higher, as the cardiac abnormalities are more serious.

Shi et al. described that BNP plasma levels rise in cirrhosis, and positively correlate with Child-Pugh score, the grade of esophageal varices, a history of spontaneous bacterial peritonitis, and the presence of ascites and collateral circulation [26]. Higher BNP levels are related to more frequent hospitalisations and higher mortality rate.

The levels of plasma BNP in cirrhosis has been investigated, but its role as prognostic marker of the disease has not been fully explored $[27,28]$. It is only used as a marker of decompensated cirrhotic cardiomyopathy, indicating the level of cardiac abnormalities, not the level of cirrhosis [21]. Latest investigations proven that BNP levels are elevated in any stage of cirrhosis. The value correlates with progression of the disease and appearance of complications.

BNP levels are higher in Child Pough B and C class than in class A, which has elevated values in comparison to healthy persons. Patients with cirrhosis complications, considering, ascites, collateral circulation, history of spontaneous bacterial peritonitis and esophageal varices are related with higher BNP levels. Its values are associated with medium term survival, implying its utility as prognostic predictor in cirrhosis [26]. These findings suggest BNP as prognostic factor of cirrhosis severity and treatment response follow up. However, there are more studies needed in this field.

\section{Conclusion}

BNP is valuable marker of heart failure used in first hand to distinguish cardiac cause of dispnea. Progression of cirrhosis leads to diastolic heart failure, and also elevation of BNP levels, whose values rise with Child Pough class, and other cirrhosis complications including esophageal varices and spontaneous bacterial peritonitis. According to that it could be a good prognostic factor and follow up marker of the disease.

\section{Competing Interests}

The authors declare that they have no competing interests.

\section{References}

1. Maeda K, Tsutamoto T, Wada A, Hisanaga T, Kinoshita M, et al. (1998) Plasma brain natriuretic peptide as a biochemical marker of high left ventricular end-diastolic pressure in patients with symptomatic left ventricular dysfunction. Am Heart J 135: 825-832.
2. Leite-Moreira AF (2006) Current perspectives in diastolic dysfunction and diastolic heart failure. Heart 92: 712-718.

3. McMurray JJ, Adamopoulos S, Anker SD, Auricchio A, Böhm M, et al. (2012) ESC Guidelines for the diagnosis and treatment of acute and chronic heart failure 2012: The Task Force for the Diagnosis and Treatment of Acute and Chronic Heart Failure 2012 of the European Society of Cardiology. Developed in collaboration with the Heart Failure Association (HFA) of the ESC. Eur Heart J 33: 1787-1847.

4. Abdeen Y, Sen P, Safdar S, Katapally R, Arqoob AA, et al. (2015) The usefulness of brain natriuretic peptide level in diagnosis and prognosis of patients admitted to critical care unit with shortness of breath. J Emerg Trauma Shock 8: 205-209.

5. Karmpaliotis D, Kirtane AJ, Ruisi CP, Polonsky T, Malhotra A, et al. (2007) Diagnostic and prognostic utility of brain natriuretic Peptide in subjects admitted to the ICU with hypoxic respiratory failure due to noncardiogenic and cardiogenic pulmonary edema. Chest 131: 964-971.

6. Omar AS, Ur Rahman M, Dhatt GS, Salami GO, Abuhasna S (2013) Dynamics of brain natriuretic peptide in critically ill patients with severe sepsis and septic shock. Saudi J Anaesth 7: 270-276.

7. Budweiser S, Luchner A, Jörres RA, Heinemann F, Hitzl AP, et al. (2007) NT-proBNP in chronic hypercapnic respiratory failure: A marker of disease severity, treatment effect and prognosis. Respir Med 101: 2003-2010.

8. Stolz D, Breidthardt T, Christ-Crain M, Bingisser R, Miedinger D, et al. (2008) Use of B-type natriuretic peptide in the risk stratification of acute exacerbations of COPD. Chest 133: 1088-1094.

9. Passino C, Poletti R, Fontana M, Vergaro G, Prontera C, et al. (2008) Clinical relevance of non-cardiac determinants of natriuretic peptide levels. Clin Chem Lab Med 46: 1515-1523.

10. Cowie MR, Jourdain P, Maisel A, Dahlstrom U, Follath F, et al. (2003) Clinical applications of B-type natriuretic peptide (BNP) testing. Eur Heart J 24: 1710-1718.

11. Daniels LB, Maisel AS (2007) Natriuretic peptides. J Am Coll Cardiol 50: 2357-2368.

12. Zhang C, Huang D, Shen D, Zhang L, Wang Y, et al. (2015) Brain Natriuretic Peptide as the long-term cause of mortality in patients with cardiovascular disease: a retrospective cohort study. Int J Clin Exp Med 8: 16364-16368.

13. Laura Leto, Marzia Testa, Mauro Feola (2015) Correlation between B-Type Natriuretic Peptide and Functional/Cognitive Parameters in Discharged Congestive Heart Failure Patients. Int J Endocrinol : 239136.

14. Chang HR, Hsieh JC, Hsu BG, Wang LY, Chen MY, et al. (2013) Inverse association of $\mathrm{N}$-terminal pro-B-type natriuretic peptide with metabolic syndrome in patients with congestive heart failure. PLoS One 8: e79096.

15. Geske JB, McKie PM, Ommen SR, Sorajja P (2013) B-type natriuretic peptide and survival in hypertrophic cardiomyopathy. J Am Coll Cardiol 61: 2456-2460.

16. Mocarzel L, Lanzieri P, Nascimento J, Peixoto C, Ribeiro M, et al. (2015) Hepatorenal syndrome with cirrhotic cardiomyopathy: case report and literature review. Case Reports Hepatol 2015: 573513.

17. Zardi EM, Abbate A, Zardi DM, Dobrina A, Margiotta D, et al. (2010) Cirrhotic cardiomyopathy. J Am Coll Cardiol 56: 539-549.

18. Páll A, Czifra A, Vitális Z, Papp M, Paragh G, et al. (2014) Pathophysiological and clinical approach to cirrhotic cardiomyopathy. J Gastrointestin Liver Dis 23: $301-310$

19. Marchetta S, Delwaide J, Lancellotti R (2015) [Cirrhotic cardiomyopathy: a brief overview]. Rev Med Liege 70: 86-91.

20. Licata A, Corrao S, Petta S, Genco C, Cardillo M, et al. (2013) NT Pro BNP Plasma Level and Atrial Volume Are Linked to the Severity of Liver Cirrhosis. PLoS One 8: e68364.

21. Wiese S, Hove JD, Bendtsen F, Møller S (2013) Cirrhotic cardiomyopathy: pathogenesis and clinical relevance. Nature Reviews Gastroenterology \& Hepatology 11: 177-186.

22. Møller S, Hove JD, Dixen U, Bendtsen F (2013) New insights into cirrhotic cardiomyopathy. Int J Cardiol 167: 1101-1108.

23. Chayanupatkul M, Liangpunsakul S (2014) Cirrhotic cardiomyopathy: review of pathophysiology and treatment. Hepatol Int 8: 308-315. 
24. Padillo J, Rioja P, Muñoz-Villanueva MC, Vallejo JA, Ciria R, et al. (2010) BNP as marker of heart dysfunction in patients with liver cirrhosis. Eur $\mathrm{J}$ Gastroenterol Hepatol 22: 1331-1336.

25. Henriksen JH, Gøtze JP, Fuglsang S, Christensen E, Bendtsen F, et al. (2003) Increased circulating pro-brain natriuretic peptide (proBNP) and brain natriuretic peptide (BNP) in patients with cirrhosis: relation to cardiovascular dysfunction and severity of disease. Gut 52: 1511-1517.

26. Shi LY, Jin R, Lin CJ, Wu JS, Chen XW, et al. (2015) B-type natriuretic peptide and cirrhosis progression. Genet Mol Res 14: 5188-5196.

27. Pimenta J, Paulo C, Gomes A, Silva S, Rocha-Gonçalves F, et al. (2010) B-type natriuretic peptide is related to cardiac function and prognosis in hospitalized patients with decompensated cirrhosis. Liver Int 30: 10591066.

28. Woo JJ, Koh YY, Kim HJ, Chung JW, Chang KS, et al. (2008) N-termina pro B-type natriuretic peptide and the evaluation of cardiac dysfunction and severity of disease in cirrhotic patients. Yonsei Med J 49: 625-631. 